\title{
Emphysematous Cholecystitis: An Unusual Presentation of a Rare Disease
}

\author{
Daniel B de Araujo*, MD, Décio V Renck, MD**, Marcelo AP de Britto, MD ${ }^{\S}$, \\ Danise S Oliveira, MD ${ }^{¥}$, Fernanda T Lauermann ${ }^{\dagger}$
}

\begin{abstract}
We report a case of radiological diagnosis of emphysematous cholecystitis, a relatively rare form of acute cholecystitis, in a non-diabetic 55-year-old woman. This case is unique given that this pathology is most commonly seen in diabetic male patients. The purpose of this article is to highlight a case of emphysematous cholecystitis in an unexpected population and discuss the clinical features, the diagnostic methods and the treatment.
\end{abstract}

\section{INTRODUCTION}

Emphysematous Cholecystitis (EC) is a severe infectious condition of the gallbladder, which occurs in approximately $1 \%$ of cases acute cholecistitis. EC is characterized by the presence of gas in the lumen of the gallbladder, as well as in its wall or adjacent tissues, in the absence of abnormal communication among the digestive and biliary system $(1,2,3)$. This gas is produced by anaerobic bacteria that invade the organ's mucosa. While the EC can be caused by microorganisms such as Klebsiella, Staphylococcus, Streptococcus and Pseudomonas species, it is most often caused by the Clostridia species $(1,4)$. As well, Escherischia Coli is also frequently present, in isolation, or as an adjuvant in the infectious process (2). These bacteria colonize the gallbladder via the bloodstream, lymphatics, or through bile itself. There is a vascular hypothesis for this entity, in which the primary insult would be occlusion of the cystic artery. An ischemic gallbladder is thought to offer

\footnotetext{
*To whom correspondence should be addressed: Daniel Brito de Araujo, Department of Internal Medicine, Hospital Escola - FAU XV de Novembro 666 / 608, 96.110-000 - Pelotas (RS) Brazil, email: danielb.araujo@bol.com.br

**Radiology Department of Santa Casa de Pelotas Hospital, and Hospital Universitário - FAU. Former Professor of Radiology in Universidade Federal de Pelotas

$\S$ Department of General Surgery, Hospital Escola - FAU

${ }^{¥}$ Family Phisicyan, Grupo Hospitalar Conceição

$\dagger$ Universidade Federal de Pelotas
}

an ideal environment for the proliferation of gas-forming bacteria $(2,4)$. This hypothesis is supported by histological evidence of arteriolar stenosis and occlusion gallbladder wall observed in EC.

\section{CASE REPORT}

We report the case of a 55-year-old female, who initially presented with abdominal pain in the right upper quadrant, in the absence of fever or vomiting. The patient was submitted to an abdominal ultrasound scan (US), due to a presumed biliary colic. The US scan demonstrated thickening of the gallbladder wall, appearing as an abnormal mass. Routine laboratory tests were normal, with the exception of alkaline phosphatase, AST and ALT, which were slightly altered. There was no history or evidence of diabetes, and fasting glucose was normal $(87 \mathrm{mg} / \mathrm{dL})$.

A CT scan was performed to elucidate the case, on account of the possible diagnosis of gallbladder tumor. It demonstrated gas inside the gallbladder, which, in the absence of enterobiliary fistula or abnormal ampulla of Vater patency, is diagnostic of Emphysematous Cholecystitis (Fig. 1). The patient underwent open cholecystectomy, receiving pre- and post-operative parenteral antibiotics. Complete remission of the symptoms was achieved, and the patient was discharged from the hospital in 5 days. 


\section{DISCUSSION}

This case is unique because the disease presents in a non-diabetic female in the fifth decade of life. Established data shows that EC occurs more frequently in the sixth and seventh decades of life, affecting diabetic patients in a larger proportion (more than half of the cases) (4,5). Unlike the regular form of acute cholecystitis, it is more common in men ( $7: 3$ male female ratio) (6). The entity is also less commonly associated with gallstone disease. Acalculous cholecystitis occurs two to three times more often in the emphysematous presentation (4). As a more severe pathology, it is associated with a greater morbidity and mortality, due to the increased risk of gangrene and perforation of the gallbladder (1).

The clinical presentation of the EC is similar to an acute cholecystitis attack, except for a rapid evolution of symptoms and a more severe abdominal pain. Sepsis occurs more frequently. In some patients, however, there may be a paucity of symptoms (2).

Radiological evaluation is the cornerstone of diagnosis. This is the only means of achieving a proper diagnose preoperatively. The demonstration of gas in the gallbladder, through plain abdominal $\mathrm{x}$-ray, ultrasound scan, and CT scan, is diagnostic of EC. Alternative diagnoses can include fistulae between the gallbladder or biliary system and gastrointestinal tract, enterobiliary anastomoses, an incompetent sphincter of Oddi, or recent endoscopic retrograde cholangiopancreatogram (ERCP) (6).

Plain X-rays are not commonly used to diagnose gallbladder disease, but they might demonstrate abnormal gas formation amongst the gallbladder tissue, air-fluid levels and curved lines of gas in the wall of the organ $(1,2)$. The radiological findings of EC can be described in three stages: Gas inside the gallbladder (Stage 1), in the gallbladder wall (Stage 2), and in the adjacent tissues (Stage 3) (3).

In most of the cases, the first imaging study applied,

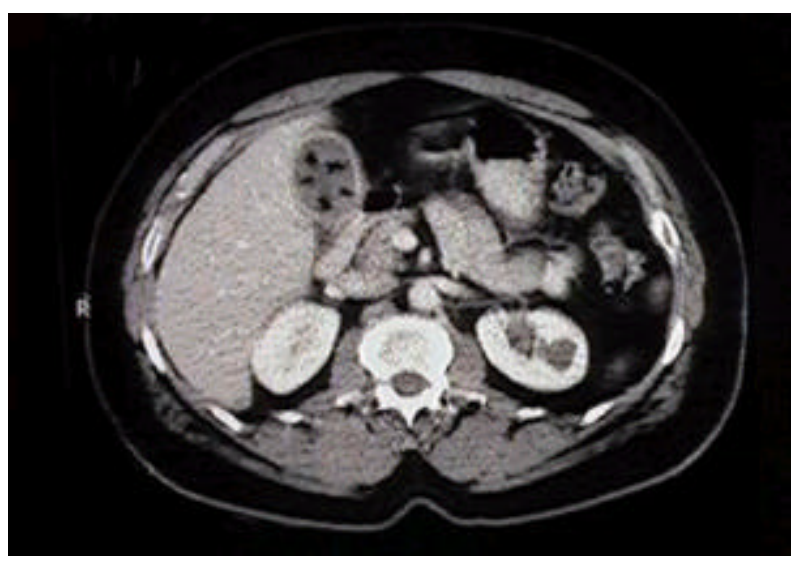

Figure $1 \mathrm{CT}$ scan of Emphysematous Cholecystisis when there is clinical suspicion of acute cholecystitis, is the ultrasound scan. Abnormal sonographic findings might be present even before gas is visible in the plain $\mathrm{x}$ ray film $(7,8)$. These findings include reverberation or the artifact known as "comet's tail", caused by an abrupt change in the acoustic impedance in the soft tissue-gas interface. A "bubbling" appearance has also been described, with small foci of gas arising in the lumen of the gallbladder. This is said to appear like "champagne bubbles" $(5,7,8)$. CT is a diagnostic method frequently used to evaluate abdominal symptoms, and virtually diagnoses EC (5). Abnormal gas formation or calcium deposits can often make the visualization of the gallbladder difficult.

Laboratory tests are non-specific, and might only show indirect evidence of acute systemic infection, such as high leukocyte count.

Adequate therapy with antibiotics, associated with cholecystectomy, in addition to rigorous glycemic control in diabetic patients, is the most efficacious therapy, with low rates of mortality $(9,10)$. The preferential approach to surgery is through laparotomy, due to the increased difficulty to perform laparoscopic surgery in these cases, with high conversion rates being reported $(11,12)$. A few studies, however, report successful laparoscopic approach in EC patients $(13,14)$. High doses of antibiotics against organisms such as Clostridium and Coliformis must be administered immediately after the diagnosis of EC. Surgery is promptly performed, to avoid complications such as spontaneous perforation, which is associated with higher rates of morbidity and mortality $(60 \%$ and $25 \%$ respectively) (4).

\section{CONCLUSION}

In summary, there is no report of diagnosis being made through high clinical suspicion, without radiological workup.

It should be emphasized that there may be inability to visualize the gallbladder in particular cases (such as some diabetic and ancillary patients) suggesting acute cholecistitis $(5,15)$. In the case reported, the failure to diagnose the pathology in the ultrasound scan occurred probably due to gas in the topography and thickening of the gallbladder wall.

A judicious search for images that might suggest abnormal gas in the right upper quadrant during ultrasound scan, or the use of additional radiologic workup (CT scan or plain x-rays) could save precious time in the evaluation of patients with such condition. It is important to face EC as a disease with a greater potential to be more complicated than in cases of nonemphysematous cholecystitis. The risk of gallbladder gangrene increases 30-fold, when compared to acute 
cholecystitis, and perforation occurs five times more often (1).

Although EC occurs more frequently in diabetic men, this diagnosis should not be ignored in non-diabetic women. In some cases, clinical signs of severe disease are not present. Biliary drainage should be considered in patients in whom surgery is contra-indicated due to severe systemic disease $(16,17)$.

\section{REFERENCES}

1. Gill KS, Chapman AH, Weston MJ: The changing face of emphysematous cholecystitis. Br J Radiol 1997;70:986-991.

2. Jolly BT, Love JN. Emphysematous cholecystitis in an elderly woman: case report and review of the literature. J Emerg Med 1993;11:593-7.

3. Hunter GD, Nardi GL. Acute emphysematous cholecystitis: an ultrasonic diagnosis. Am J Roentgend 1980;134:592.

4. Waisberg J, Bento JA, Oriente R, et al. Colecistite aguda enfisematosa. Relato de um caso e revisão da literatura. Arq Gastroenterol 1987;24:30-35.

5. Mammen L, Watkins GE. Case of the month: Emphysematous cholecystitis. Appl Radiol 2000;Oct 36-38.

6. Abengowe CU, McMamon PJM. Acute emphysematous cholecystitis. Can Med Assoc J 1974;111:1112.

7. Wu CS, Yao WJ, Hsiao CH. Effervescent gallbladder: sonographic findings in emphysematous cholecystitis. J Clin Ultrassound 1998;26:272-75.
8. Fraquet T, Bescos JM, Barberena J, Montes M: Acoustic artifacts and reverberation shadows in gallbladder sonogranms: Their cause and clinical implications. Gastro Intest Radiol 1990,;15:223-228. 9. Rosoff L, Meyers H. Acute emphysematous cholecystitis. An analysis of ten cases. Am J Surg 1966;111:410-414.

10. Garcia-Sancho Tellez L, Rodrigues-Montes JA, Fernandez de Lis S, Garcia-Sancho Manrtin L. Acute emphysematous cholecystitis. Report of twenty cases. Hepatogastroenterology 1999;46:2144-8. 11. Lilemoe, KD. Surgical treatment of biliary tract infections. The Amer Surg 2000;66:138-144.

12. Prakash K, Jacob G, Lekha V, Venugopal A, Venugopal B, Ramesh H. Laparoscopic cholecystectomy in acute cholecystitis. Surg Endosc 2002;16:180-3.

13. Banwell PE, Hill AD, Menzies-Gow D. Laparoscopic cholecystectomy: safe and feasible in emphysematous cholecystitis. Surg Laparosc Endosc 1994;4(3):189-91.

14. Hazey JW, Brody FJ, Rosenblatt SM, Brodsky J, Malm J, Ponsky JL. Laparoscopic management and clinical outcome of emphysematous cholecystitis. Surg Endosc 2001;15:1217-20. 15. Puc MM, Trans HS, Wry PW, Ross SE. Ultrasound is not a useful screening tool for acute acalculous cholecystitis in critically ill trauma patients. Am Surg 2002;68:65-9.

16. Slot WB, Ooms HW, Van der Werf SD, Puylaert JB.

Percutaneous gallbladder drainage in emphysematous cholecystitis. Neth J Med 1995;46:86-9.

17. Távora I, Alvares P, Tavares A, Vitor L, Fernandes A, Afonso JG. Percutaneous cholecystectomy. Alternative therapy for acute emphysematous cholecystitis. Acta Med Port 1995;8:39-41.

Daniel Brito de Araujo is a second year resident in Internal Medicine of the Federal University of Pelotas, and obtained his medical degree at the same institution. His area of interest includes Rheumatology and Imunology, and he hopes to get into a residency program in Rheumatology.

Décio Valente Renck is a Radiologist in Santa Casa de Pelotas Hospital, with his practice based in computed tomography and magnetic resonance imaging. He obtained his medical degree in the Catholic University of Pelotas, and Nuclear Medicine formation in Mãe de Deus Hospital.

Marcelo A. P. de Britto is a second year sugical resident of the Federal University of Pelotas, and obtained his medical degree at the same institution. He is currently the chief surgical resident at Hospital Escola / UFPel. His area of interest includes colorectal surgery.

Danise Senna Oliveira is a first year resident in Family Physician Practice in Conceição Hospital. She obtained her medical degree in the Federal University of Pelotas. Her area of interest includes epidemiological populational studies and general practice.

Fernanda Tcatch Lauermann is a 5th year medical student at the Federal University of Pelotas, and is currently working at the Epidemiology Research Center of that institution. Her area of interest includes Internal Medicine and Dermatology, and she hopes to get into a residency program in Internal Medicine. 